\title{
Efficiency Improvement Analysis for Recent High-Efficient Solar Cells
}

\section{Ashrafun Nushra Oishi, Meer Shadman Shafkat Tanjim, M. Tanseer Ali}

\begin{abstract}
The total electricity demand of the whole earth, can be theoretically satisfied by harnessing the unlimited photon energy of the alpha source, the sun. Absorbing the solar power in a full efficient way is still on progress, due to the limitation of our solar cell technology. On commercial aspects, it is also promising but not up to the mark. Recent high efficient solar cell still leaves more space to improve the cell efficiency. On these circumstances, the use of Graphene, MultiJunction Cells and Quantum Dot Cells will be helpful to increase the rate of recent research flow. This paper visualizes GaAs, InP, CdTe and Graphene implementations on four proposed basic models, which have showed a positive impact to overcome the losses and SQ limits. These models also postulate the maximization of the solar cell efficiency, omitting the corresponding losses along with maintaining the inter-junction relation suitably.
\end{abstract}

Keywords-Solar Cell Efficiency, Multi-Junction, Quantum Dot Cell, Cell Efficiency Improvement, Graphene, Loss Analysis, Absorptivity, Transparency, Voltage Loss, Fill Factor Loss, Optical Loss, Electrical Loss, Low Energy Photon, Excess Energy Photon, Sub-Band Gap, Recombination Loss, Resistive Loss, Encapsulation, MPPT.

\section{INTRODUCTION}

Among the other available renewable sources, Solar energy is the most unlimited energy. According to the US Department of Energy, the amount of power from the sun in a single hour that strikes the Earth is more than the entire world consumes in a year. Each hour 430 quintillion Joules of energy from the sun hits the Earth. In comparison, the total amount of energy that all humans use in a year is 410 quintillion Joules. To be noted that, 430 Exajoules (EJ) is equal to $119444444 \mathrm{GWh}$ and $410 \mathrm{EJ}$ is equal to 113888888 GWh. The MIT Physics Professor Washington Taylor explained that a total of 173,000 terawatts (trillions of watts) of solar energy strikes the earth continuously. That is more than 10,000 times the world's total energy use. And that energy is completely renewable until the sun's Lifetime. It is still acceptable that, this Energy source has still 5 billion

\section{Ashrafun Nushra Oishi}

American International University-Bangladesh

Dhaka, Bangladesh

ashrafun_nushra@yahoo.com

\section{Meer Shadman Shafkat Tanjim}

American International University-Bangladesh Dhaka, Bangladesh

meer.tanjim@yahoo.com

\section{Tanseer Ali}

American International University-Bangladesh Dhaka, Bangladesh

tanseer@aiub.edu more years to be utilized. However, fully harnessing the total amount of energy which hits per square feet of the earth, is a great challenge over material, efficiency, cost, technology. But at any cost to also maintain a clean environment for the future, making the solar cell efficiency higher in every aspect, should be the main concern.

Usually, Mono-crystalline cell is around 20\% efficient commercially. It is usually shaped as single hexagonal size for scaling criteria. But theoretically it achieved around 29\% efficiency. Amorphous thin film is $10 \%$ efficient and it is good for its transparency along with low cost. Polycrystalline is around $15 \%$ efficient at lower cost category. Considering the space congestion this type of cell is designed in square shape. Reaching $16.5 \%$ efficiency, CdTe thin film cell is popular for its lower expense and large number of array deployment facility [1]. CdInGa Selenide thin film cell is around $20 \%$ efficient.

Hybrid Solar Cell with Perovskite has the efficiency range around $29 \%$ to $32 \%$ [2]. GaAs Multi-Junction Cell, having maximum $42.4 \%$ efficiency is used for expensive commercial purpose [3-5]. Adjusting doping level and the size of emitter-base layers, the efficiency of multi-junction cell can be improved [6-7].

Solar cell is not achieving around $100 \%$ efficiency due to several loss factors [8-9]. Depending on some criteria, power loss analysis has been done to avoid this efficiency loss. Maximum Power Point Tracking (MPPT) System cannot be achieved for numerous reasons. We cannot choose randomly a material with a lower band gap. Because, the band gap also determines the strength (voltage) of electric field [10]. And if it is too low, then we can gain some extra current (by absorbing more photons). But on the other hand, we will be introduced to a small voltage also.

Energy conversion phenomena is also needed to be taken care of. Because few times after energy conversion, electron charge travels to a side and also to load area. In the meantime, these flows sometimes get resistive behavior due to lack of space shortage in the path of charge flow. For this, access charge gets trapped and create temperature rise in the system [11].

High generation of electron and hole pair, rises the congestion of charge carriers. As a result, the conversion efficiency reduces rapidly. The analysis for charge carrier separation [14], dynamics, efficiency and stability should be taken care of, while designing solar cells [11].

In solar cell, temperature gets a high rise due to the sun radiation. To reduce this heat, cavity base high pressurized air was introduced [12]. Water cooling made this step much easier but due to less boiling point level of water, water become non-suitable to transfer the heat from the cell. Accessing several heat transfer systems, some got little bit of efficient. From the analysis, a highly heat transfer system 
should be introduced to carry the heat from the cell and sink it to the air or other source.

Since Graphene can be engineered as slight superconductor and can be materialized for transparency, it can be used in this case to full fill the desire of encapsulation layer, heat transfer layer and electrode layer [13].

Band gap has a direct relation to the solar energy harness. Suppose, a solar cell is designed with silicon having $1.12 \mathrm{eV}$ bandgap. That means from $0.38 \mu \mathrm{m}$ to $1.11 \mu \mathrm{m}$ wavelength's photon are usable for the cell to convert it to electron-hole pair [15]; but other photons $(1.12 \mu \mathrm{m}$ to $2.5 \mu \mathrm{m})$ are wasted for the cell. This happens because, for $1.12 \mathrm{eV}$ band gapped material, photons with wavelengths longer than $1.11 \mu \mathrm{m}$ have less energy than the band-gap energy of silicon (1.12 $\mathrm{eV})$ and photons with wavelengths shorter than $1.11 \mu \mathrm{m}$ have more than enough energy to excite an electron.

Graphene has a unique set of properties which set it apart from other materials. In proportion to its thickness, it is about 100 times stronger than the strongest steel. It conducts heat and electricity very efficiently and is nearly transparent. Researchers have identified the bipolar transistor effect, ballistic transport of charges and large quantum oscillations in the material [16]. Graphene's reduced band gap (nearly zero) makes graphene a wonderful candidate to use in PV cells. It can absorb photons with energy at every frequency. Photons of different frequencies of light are converted to electrons with matching energy levels. A material with a band gap can't convert wavelengths of light that correspond to the forbidden energy states of the electrons. Almost zero band gap means every wavelength is penetrable into the cell.

Non-covalent functionalized CVD-grown graphene shows a good conductivity and can have up to $0.55 \mathrm{~V}$ open circuit voltage, a fill factor of 55\% and a PCE of $1.71 \%$. The flexibility of graphene allows the solar cell to bend up to $78^{\circ}$ more than pure ITO electrodes [17-18]. Moreover, Doped Graphene Solar Cell [19], QD Graphene Solar Cell, Graphene Tandem Solar Cell, Graphene BulkHeterojunction Solar Cell [20], Graphene Schottky GaAs Solar Cell [21] [5], created an addition to advance research on efficient solar cell technology [22].

\section{Proposed IMPRovised SOlar CELL}

Taking the possible loss facts, improvisation of solar cell can be done both theoretically and practically [23-26]. Taking a model as reference, makes the path easier for improvisation. Here, a 2D model of GaAs was the reference. From that model an improvised solar cell are proposed considering several phenomena which will be easier for future commercialization of power generation. These models can be useful for future multi-junction coupled solar cell.

\section{A. Existing Simple GaAs Model:}

The reference base model is a GaAs 2D model where, moderate $\mathrm{p}-\mathrm{n}$ doping and high $\mathrm{p}+$ or $\mathrm{n}+$ doping was created. Based on the model other combination of PV cell are done (such as - multi-junction solar cell). Silicon based solar cell is also leading the edge of efficiency but other models will be helpful to get sandwiched for future multi-junction solar cell.

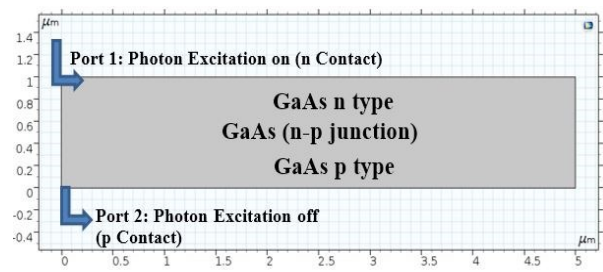

Fig. 1: Reference GaAs Solar Cell Basic Model

\section{B. Proposed Graphene-GaAs-Graphene 2D model:}

As Graphene has advantage along with GaAs in Solar Cell, a first try of the model has been made to test the variation. Due to Graphene's electron super-conductivity and transparency, it is placed on the top. And for its thermal conductivity and all solar spectrum absorption quality, it is placed on the last layer also. In the middle GaAs is placed due to its direct bandgap and crystal structure it is considered as the main doped layer of the cell [27-28].

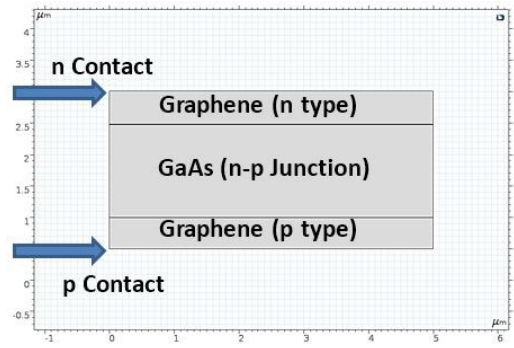

Fig. 2: Proposed Graphene-GaAs-Graphene 2D Model

\section{Proposed Graphene-CdTe-GaAs-InP 2D model:}

This model is the variation of some suitable material designable for Solar Cell. This basic model has been treated like multi-junction but assembled like union form. The material order from top to bottom layer is Graphene, CdTe, GaAs, InP consecutively.

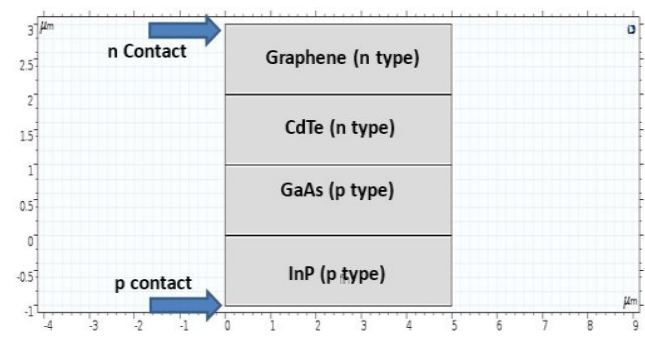

Fig. 3: Proposed Graphene-CdTe-GaAs-InP 2D Model.

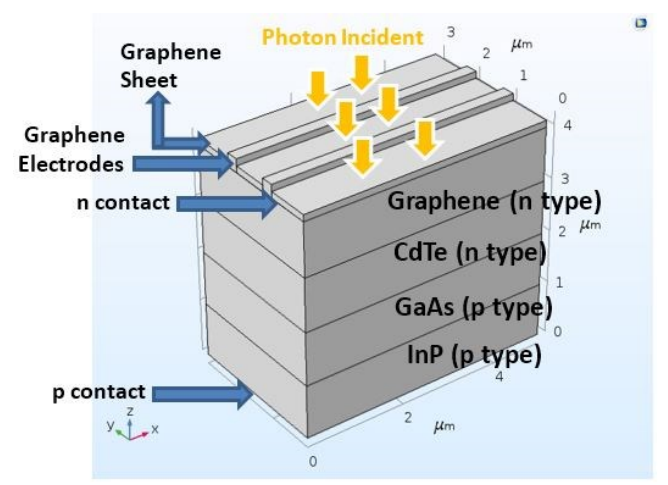

Fig. 4: 3D version of Proposed Graphene-CdTe-GaAs-InP model. 


\section{Proposed CdTe-GaAs-InP-Graphene 2D model:}

This model is similar to the previous one but the layer size has difference and the Graphene is layered as the last layer of the Cell to test the phenomena. This basic model is treated like multi-junction but assembled like union form.

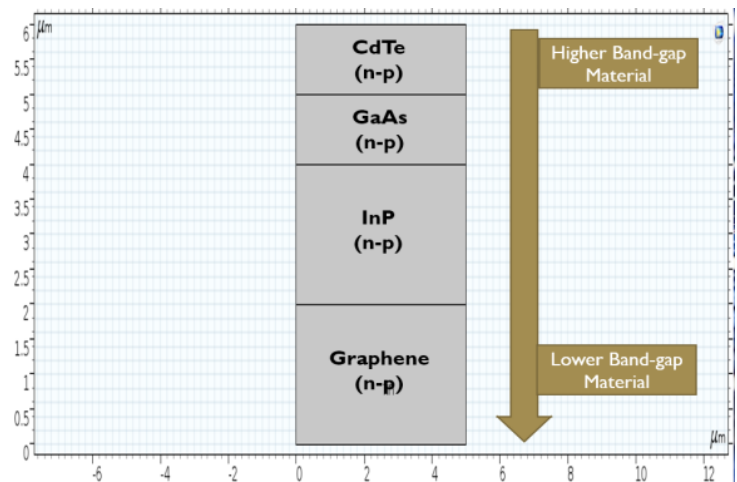

Fig. 5: Proposed CdTe-GaAs-InP-Graphene 2D Model.

The material order from top to bottom layer is CdTe, GaAs, InP, Graphene consecutively. The last two layers are doubled from the first two layers.

\section{Simulated Results AND ANALYSis}

Every proposed model is tested in different simulation environment. With the best fitted environment, results are being plotted. Somehow, more simulation environment can be approached on these models to make it even more efficient.

Semiconductor and electromagnetic wave physics have been chosen for the model. To couple the physics, a software built-in coupler theory "Semiconductor - Electromagnetic Wave Coupler" is attached to the model. Mesh has been prepared for that.

\section{A. Existing Simple GaAs 2D Model:}

The existing model is changed a little bit and the output has been balanced.

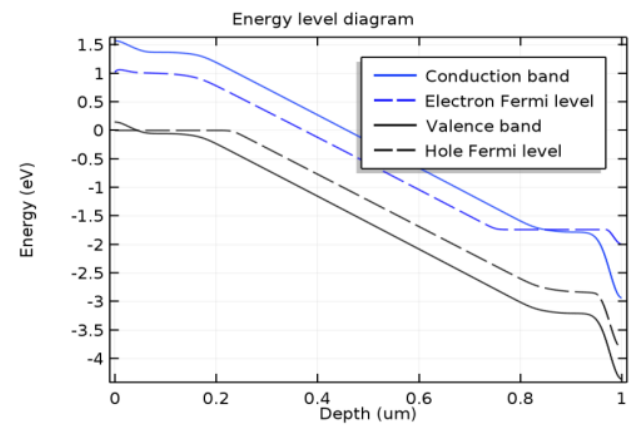

Fig. 6: Energy band diagram for GaAs cell

\section{B. Proposed Graphene-GaAs-Graphene 2D Model:}

This model is simulated in a union form. For which the three layers are combined into one layer. That means, it will behave like a compound material layer. As a result, Graphene-GaAs-Graphene, the energy level diagram comes as follows. On the zero region, the electron fermi-level and hole fermi-level have been detected. One the positive side 0.10 Conduction band has been detected and valence band have been detected on the negative 0.16 level. For which the total band gap between conduction and valence band seems $0.26 \mathrm{eV}$.

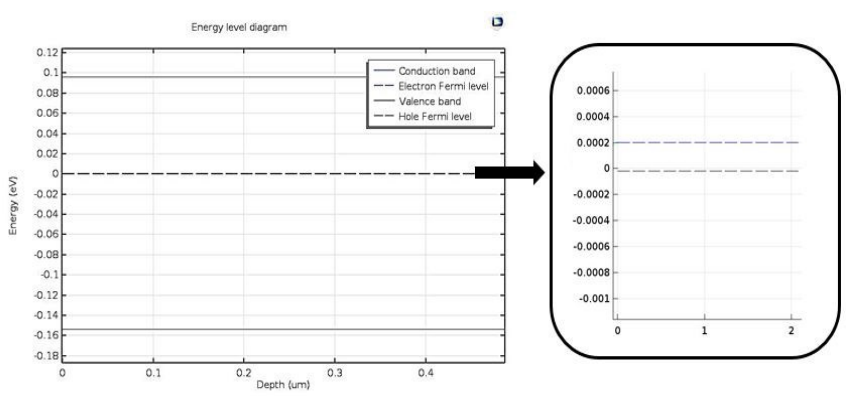

Fig. 7: Energy band diagram for Graphene-GaAs-Graphene cell.

The band-gap, $\mathrm{E}_{\mathrm{g}}$ for silicon is $1.12 \mathrm{eV}$, which means an electron needs to acquire that much energy to free itself from the electrostatic force that ties it to its own nucleus (to jump into the conduction band). For photovoltaics, the energy source is photon of electromagnetic energy from the sun. When a photon with more than $1.12 \mathrm{eV}$ of energy is absorbed by a solar cell, a single electron may jump to the conduction band. Thus, photons with enough energy create hole-electron pairs in a semiconductor.

For Silicon with $1.12 \mathrm{eV}$ band gap; photons with wavelengths longer than $1.11 \mu \mathrm{m}$ have less energy than the band-gap energy of silicon $(1.12 \mathrm{eV})$, so all their energy is wasted as heat within the cell.

But for this model, as it is entirely $0.26 \mathrm{eV}$ in band gap, so only $0.26 \mathrm{eV}$ or $260 \mathrm{meV}$ is needed to create the electronhole pair on the PV cell. That means, up to $4.77 \mu \mathrm{m}$ wavelength of the spectrum can be absorbed. According to solar spectrum, $2.5 \mu \mathrm{m}$ is the highest wavelength for photon energy. That means all the photon of solar spectrum can be absorbed.

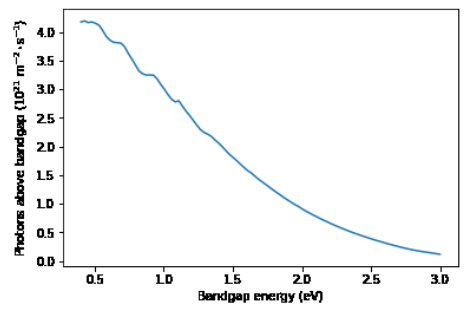

Fig. 8: Bandgap energy VS Photons above bandgap.

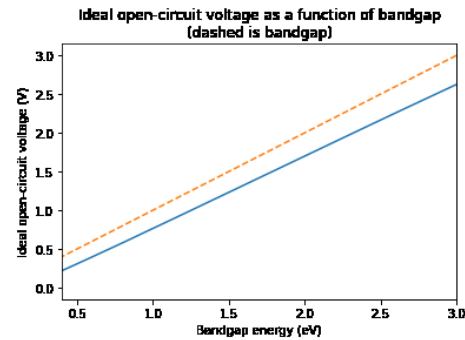

Fig. 9: Bandgap energy VS $V_{\text {oc }}$ for usual solar cell [29]. 
From this graph, we can see the $\mathrm{V}_{\text {oc }}$ is so less for $0.26 \mathrm{eV}$. If this 0.5 Volt is needed to make higher than we can use an external voltage just to initialize it and always connect the solar cell in series. Though the voltage is getting lesser for the model's band gap $(0.26 \mathrm{e} \mathrm{V})$, it can be overcome by wiring the solar cell in series for the panel, which will increase the voltage level. It is like same current with additive voltage value. And for the extra charge solution, as the PV charge controller is getting smarter in manufacturing, we can store the extra charge to battery.

In the best possible case, the QFL (Quasi-Fermi Level) splitting is equal to the external voltage (in reality, it may be larger than the external voltage). Normally, this is true because, to get a net flow of photo-generated electrons into the cathode lead, the electron QFL has to tilt downward towards the cathode lead, and likewise to get a net flow of photogenerated holes into the anode lead, the hole QFL has to tilt upwards towards the cathode lead. However, in a tandem cell, the QFLs repeatedly split apart and come back together, such that the external voltage can be much greater than the QFL splitting at any given point.

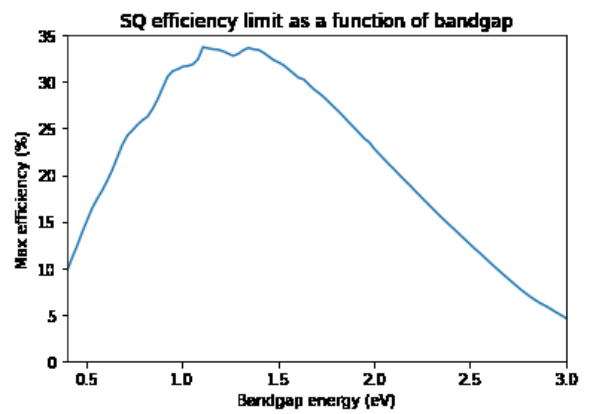

Fig. 10: Bandgap energy VS SQ Max- $\eta$ Limit, for usual solar cell [29].

According to Shockley-Queisser limit, $1.2 \mathrm{eV}$ to $1.6 \mathrm{eV}$ Band-gapped solar cell can achieve higher efficiency ( $34 \%)$. But as few things are taken on account then, it will not be the limit at all to SQ limit as the SQ theory. Those are -

Table 1 Model-B Advantage, Over SQ Limit

\begin{tabular}{|l|l|}
\hline $\begin{array}{c}\text { Challenges Over SQ Limit and other } \\
\text { Limit }\end{array}$ & \multicolumn{1}{|c|}{ Solution on the model } \\
\hline $\begin{array}{l}\text { More photons means more Electron- } \\
\text { hole pair generation. Extracting the } \\
\text { flow of electron as quick as Possible is } \\
\text { a major drawback for the cell, } \\
\text { efficiency will reduce if not wept away. }\end{array}$ & $\begin{array}{l}\text { Graphene (as superconductor) } \\
\text { has been used on the cathode } \\
\text { side for Electron transportation. }\end{array}$ \\
\hline $\begin{array}{l}\text { Due to excess photon than assumption, } \\
\text { the PV cell will be heated up. This heat } \\
\text { will change the device configuration } \\
\text { and will increase the recombination rate } \\
\text { of the pairs. }\end{array}$ & $\begin{array}{l}\text { Graphene (as thermal conductor } \\
\text { has been used to allow the heat } \\
\text { passes away to other place. }\end{array}$ \\
\hline $\begin{array}{l}\text { Photons frequency get lower when it is } \\
\text { of higher Wavelength. For this reason, } \\
\text { the wave may get trap at the middle. }\end{array}$ & $\begin{array}{l}\text { GaAs is placed in between } \\
\text { Graphene to divide } \\
\text { conversion rate into top layer } \\
\text { and bottom layer so that no trap } \\
\text { creates an unbalance situation }\end{array}$ \\
\hline $\begin{array}{l}\text { As solar spectrum exists from } 350 \text { nm } \\
\text { to 2.5 } \mu \text { m, Light needs to be confined } \\
\text { within the area. An area with } 3 \mu \mathrm{m} \text { will } \\
\text { absorb the incoming photon. }\end{array}$ & $\begin{array}{l}\text { The cell size is limited to } 3 \mu \mathrm{m} \text {. } \\
\text { For this area, The photon will } \\
\text { enter the cell from graphene } \\
\text { layer and the rest process will be } \\
\text { the conversion process. }\end{array}$ \\
\hline
\end{tabular}

\section{Proposed Graphene-CdTe-GaAs-InP 2D Model:}

This model is simulated in a union form. For which, the four layers are combined together. As a result, GrapheneCdTe-GaAs-InP layer's energy level diagram comes as follows. On the zero region, the Electron Fermi level and Hole Fermi Level was detected. One the positive $1.2 \mathrm{eV}$ side, Conduction band has been detected and Valence band has been detected on the negative 0.2 level. For which the total band gap between conduction and valence band seems 1.42 $\mathrm{eV}$.

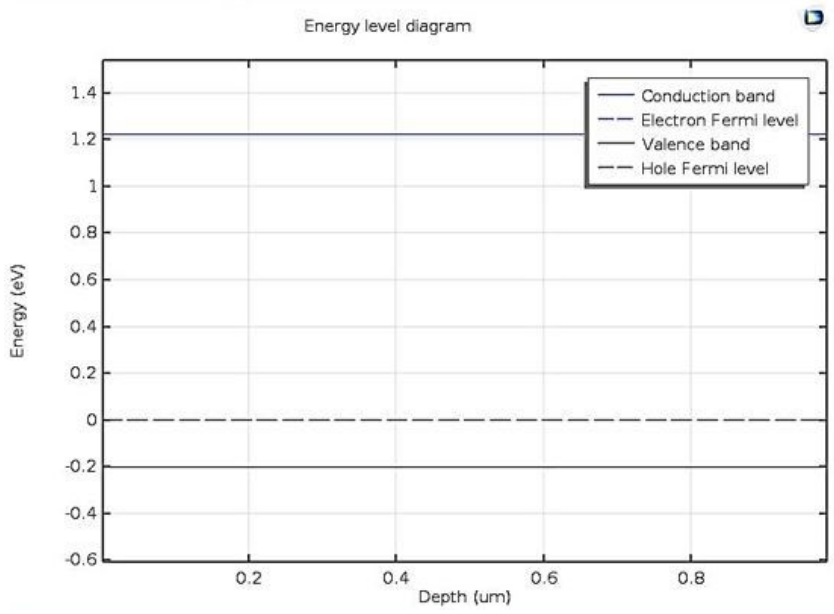

Fig. 11: Energy band diagram for Graphene-CdTe-GaAs-InP cell.

For this model, it is entirely $1.42 \mathrm{eV}$ in band gap, so only $1.42 \mathrm{eV}$ is needed to create the electron-hole pair on the PV cell. That means, up to $874 \mathrm{~nm}$ or $0.87 \mu \mathrm{m}$ wavelength of the spectrum can be absorbed.

According to Solar Spectrum, $2.5 \mu \mathrm{m}$ is the highest wavelength for photon energy. That means $23.8 \%$ wavelength of solar spectrum can be absorbed. But from the fig. 8, around $50 \%$ of the photon of solar spectrum is incident for $1.42 \mathrm{eV}$ band gap. And it will have an acceptable $\mathrm{V}_{\mathrm{oc}}$ as per fig. 9 plot.

Moreover, from the fig. 10, the maximum efficiency will be $34 \%$ in SQ Limit, Which will be more efficient over recent commercial solar cell because, this model has solution to overcome SQ Limit. The solutions are-

Table 2 Model-C Advantage, Over SQ and Other Limit

\begin{tabular}{|l|l|}
\hline \multicolumn{1}{|c|}{$\begin{array}{c}\text { Challenges Over SQ Limit and } \\
\text { other Limit }\end{array}$} & \multicolumn{1}{|c|}{ Solution on the model } \\
\hline $\begin{array}{l}\text { [SQ-L] More Electron-hole pair } \\
\text { generation VS high recombination } \\
\text { Problem. }\end{array}$ & $\begin{array}{l}\text { Graphene (as superconductor) has } \\
\text { been used on the cathode side for } \\
\text { Electron transportation. }\end{array}$ \\
\hline $\begin{array}{l}\text { Due to non-absorption of 50\% } \\
\text { photon, heat will be generated. The } \\
\text { PV cell will be heated up. This heat } \\
\text { will change the device configuration } \\
\text { and increase the recombination rate } \\
\text { of the pairs. }\end{array}$ & $\begin{array}{l}\text { Graphene as thermal conductor) } \\
\text { has been used to allow the heat } \\
\text { away to other place. }\end{array}$ \\
\hline $\begin{array}{l}\text { [SQ-L] Responding the Excitons to } \\
\text { be converted into electron-hole pair } \\
\text { more. }\end{array}$ & $\begin{array}{l}\text { QD CdTe application and } \\
\text { Graphene's Electron Transportation } \\
\text { will be helpful. }\end{array}$ \\
\hline & $\begin{array}{l}\text { GaAs is placed in between } \\
\text { Graphene to divide the conversion } \\
\text { rate into top layer and bottom layer } \\
\text { so that no trap creates an unbalance } \\
\text { situation. }\end{array}$ \\
\hline Conversion Efficiency and Weight \\
\hline
\end{tabular}


Solar spectrum exists from $350 \mathrm{~nm}$ to $2.5 \mu \mathrm{m}$. The depth of the solar cell will be as the wavelength size to confine the incident light. The cell depth for the model should be atleast $0.87 \mu \mathrm{m}$ to absorb the incoming photon.

\section{Proposed CdTe-GaAs-InP-Graphene 2D Model:}

This model is simulated in an assembly form. As a result, CdTe-GaAs-InP-Graphene layers will be different. But somehow there is a whole energy level diagram for the model which shows best output as negative energy level have some significant meaning in some high efficiency solar cell result [6]. On the negative $5.5 \mathrm{eV}$ region, the electron fermi level and hole fermi level have been detected. One the negative $4.85 \mathrm{eV}$ side, Conduction band has been detected and Valence band has been detected on the negative 6.48 level. For which the total band gap between conduction and valence band seems $1.63 \mathrm{eV}$.

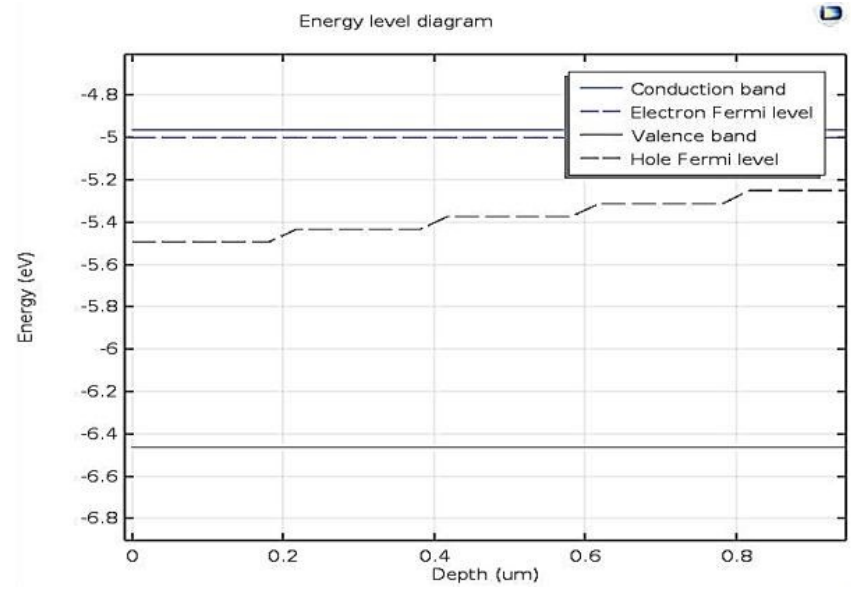

Fig. 12: Energy band diagram for CdTe-GaAs-InP-Graphene cell.

For this model, it is entirely $1.63 \mathrm{eV}$ in band gap, $1.63 \mathrm{eV}$ is needed to create the electron-hole pair on the PV cell. But as the layer is in assembly mode, the cell accommodates four types of original bandgap material. And the bandgaps are $1.5 \mathrm{eV}, 1.424 \mathrm{eV}, 1.34 \mathrm{eV}$ and $0.250 \mathrm{eV}$ from top layer consecutively.

That means, on 1st layer (CdTe) $827 \mathrm{~nm}$ or $0.827 \mu \mathrm{m}$; on 2nd layer (GaAs) $871 \mathrm{~nm}$ or $0.871 \mu \mathrm{m}$; on 3rd layer (InP) $925 \mathrm{~nm}$ or $0.925 \mu \mathrm{m}$; on last layer (Graphene) $4.96 \mu \mathrm{m}$ (highest $2.5 \mu \mathrm{m}$, according to solar spectrum) wavelength of the spectrum can be absorbed.

According to Solar Spectrum, $0.360 \mu \mathrm{m}$ to $2.5 \mu \mathrm{m}$ is the highest wavelength for photon energy. Here, from 1 st to $3 \mathrm{rd}$ Layer $0.360 \mu \mathrm{m}$ to $0.925 \mu \mathrm{m}$, $(26.4 \%$ wavelength of solar spectrum); and on last layer of Graphene, up to $2.5 \mu \mathrm{m}$; (rest $73.6 \%$ wavelength of solar spectrum), can be absorbed. That means almost all the wavelength will be absorbed in this hybrid band gapped cell. But from the fig. 8, around $80 \%$ of the photon of solar spectrum is incident for the model. And it will have an acceptable $\mathrm{V}_{\text {oc }}$ as per fig. 9 plot.

Moreover, from the fig. 10, the maximum efficiency will be highest in SQ Limit, Which will be more efficient over recent commercial solar cell because, this model also has solution to overcome SQ Limit. The solutions are-
Table 3 Model-D Advantage, Over SQ and Other Limit

\begin{tabular}{|c|c|}
\hline $\begin{array}{c}\text { Challenges Over SQ Limit and } \\
\text { other Limit }\end{array}$ & Solution on the model \\
\hline $\begin{array}{l}\text { [SQ-L] More Electron-hole pair } \\
\text { generation VS high recombination } \\
\text { Problem. }\end{array}$ & $\begin{array}{l}\text { Graphene (as superconductor) will } \\
\text { be used used on the cathode side for } \\
\text { Electron transportation. }\end{array}$ \\
\hline $\begin{array}{l}\text { [SQ-L] Responding the Excitons to } \\
\text { be converted into electron-hole pair } \\
\text { more. }\end{array}$ & $\begin{array}{l}\text { QD CdTe application and } \\
\text { Graphene's Electron Transportion } \\
\text { will be helpful. }\end{array}$ \\
\hline Conversion Efficiency and Weight & $\begin{array}{l}\text { QD CdTe, GaAs, InP and Graphene } \\
\text { has been used to balance the } \\
\text { conversion efficiency }\end{array}$ \\
\hline $\begin{array}{l}\text { Solar spectrum exists from } 360 \mathrm{~nm} \\
\text { to } 2.5 \mu \mathrm{m} \text {. The depth of the solar } \\
\text { cell will be as the wavelength size to } \\
\text { confine the incident Light. The cell } \\
\text { depth for the model should be } \\
\text { atleast } 3 \mu \mathrm{m} \text { to absorb the incoming } \\
\text { photon. }\end{array}$ & $\begin{array}{l}\text { The cell size is limited to } 1 \mu \mathrm{m} \text { for } \\
\text { CdTe and GaAs as its incident light. } \\
\text { And for InP and Graphene } 2 \mu \mathrm{m} \\
\text { each is allocated. For this sizing, } \\
\text { The corresponding photon will enter } \\
\text { the cell from each of the layer and } \\
\text { the rest process will be the } \\
\text { conversion process. }\end{array}$ \\
\hline $\begin{array}{l}\text { [SQ-L] More photons means more } \\
\text { Electron-hole pair generation. } \\
\text { Extracting the flow of electron as } \\
\text { quick as Possible is a major } \\
\text { drawback for the cell, efficiency } \\
\text { will reduce if not wept away. }\end{array}$ & $\begin{array}{l}\text { In practical representation Graphene } \\
\text { (as superconductor) will be used on } \\
\text { the cathode side for Electron } \\
\text { transportation. }\end{array}$ \\
\hline $\begin{array}{l}\text { [SQ-L] Due to excess photon, the } \\
\text { PV cell maybe be heated up. This } \\
\text { heat will change the device } \\
\text { configuration and will increase the } \\
\text { recombination rate of the pairs. }\end{array}$ & $\begin{array}{l}\text { Graphene (as thermal conductor has } \\
\text { been used at the bottom to allow the } \\
\text { heat passes away to other place. }\end{array}$ \\
\hline $\begin{array}{l}\text { [SQ-L] Removing the hot electron } \\
\text { from band edges during generation. }\end{array}$ & $\begin{array}{l}\text { GaAs is used to subdue it by the } \\
\text { help of graphene electron } \\
\text { transportation }\end{array}$ \\
\hline $\begin{array}{l}\text { Photons frequency get lower when it } \\
\text { is of higher Wavelength. For this } \\
\text { reason, the wave may get trap at the } \\
\text { middle. }\end{array}$ & $\begin{array}{l}\text { GaAs and InP is placed before } \\
\text { Graphene to divide the conversion } \\
\text { rate before bottom layer so that no } \\
\text { trap creates an unbalance situation }\end{array}$ \\
\hline
\end{tabular}

\section{CONCLUSION}

Four efficient solar cell models are proposed with proper simulation, on the basis of possible solution facts. According to the simulation results, the energy level diagram seems good, as it should be on the high-efficient solar cells [6]. If these solar cells contain no optical loss with radiative recombination, it can still reach to $85 \%$ efficiency [30]. But the proposed model will cross the barrier over 95\%. The application of Graphene ensures it. These proposed four basic models will be the gateway of future high-efficient solar cell with the possibility of $85 \%$ to $95 \%$ overall efficiency. The usage of Graphene (for heat and electron conduction, along with internal photon conversion activity) and CdTe (for Quantum Dot purpose) with GaAs and InP will create a revolution on these models.

\section{REFERENCES}

[1] Vipin Kumar, "Electrical properties of cadmium telluride screenprinted films for photovoltaic applications," Chalcogenide Letters, 5. 2008, pp. 171-176.

[2] M. Bodiul Islam, M. Yanagida, Y. Shirai, Y. Nabetani, K. Miyano, "Highly stable semi-transparent MAPbI3 perovskite solar cells with operational output for $4000 \mathrm{~h}$," Solar Energy Materials and Solar Cells, Volume 195,2019, pp. 323-329. 
[3] Wang, X., et al. "Design of GaAs Solar Cells Operating Close to the Shockley-Queisser Limit". IEEE Journal of Photovoltaics. 2013. 3 (2): 737 .

[4] Hector Cotal, Chris Fetzer, Joseph Boisvert, Geoffrey Kinsey, Richard King, Peter Hebert, Hojun Yoon and Nasser Karam , "III-V multijunction solar cells for concentrating photovoltaics ," The Royal Society of Chemistry 2009 , Energy Environ. Sci., 2009, 2, pp. 174192

[5] Jie W., Zheng F., Hao J., "Graphene/gallium arsenide-based Schottky junction solar cells,” App. Phys. Lett., 2013, 103, 233111.

[6] Eli Yablonovitch, Owen D Miller, S. R. Kurtz, "The opto-electronic physics that broke the efficiency limit in solar cells", 2012 38th IEEE Photovoltaic Specialists Conference. 2012 p. 001556.

[7] Roland Scheer, Hans-Werner Schock, "Introduction", Chalcogenide Photovoltaics. 2011. pp. 1-8.

[8] M. Taguchi et al., "24.7\% Record Efficiency HIT Solar Cell on Thin Silicon Wafer," IEEE Journal of Photovoltaics, vol. 4, no. 1, 2014, pp. 96-99.

[9] Prabhakaran Selvaraj, Hasan Baig, Tapas K. Mallick, Jonathan Siviter, Andrea Montecucco, Wen Li, Manosh Paul, Tracy Sweet, Min Gao, Andrew R. Knox, Senthilarasu Sundaram, "Enhancing the efficiency of transparent dye-sensitized solar cells using concentrated light," Solar Energy Materials and Solar Cells, Volume 175, 2018, pp. 29-34.

[10] Berthod, C., Kristensen, S. T., Strandberg, R., Odden, J. O., Nie, S., Hameiri, Z., \& Satre, T. O. "Temperature Sensitivity of Multicrystalline Silicon Solar Cells", IEEE Journal of Photovoltaics, 2019, pp. 1-8

[11] Wang, B., Iocozzia, J., Zhang, M., Ye, M., Yan, S., Jin, H., Lin, Z. "The charge carrier dynamics, efficiency and stability of twodimensional material-based perovskite solar cells," Chemical Society Reviews, 2019, pp. 1-38.

[12] Swar A. Zubeer1, H.A. Mohammed, and Mustafa Ilkan, "A review of photovoltaic cells cooling techniques”, E3S Web of Conferences 22, 00205, 2017, pp. 1-2.

[13] Li P., Chen C., Zhang J., Li S., Sun B., Bao Q., "Graphene-based transparent electrodes for hybrid solar cells," Frontiers in Materials, $2014,1,26$

[14] U. Würfel, A. Cuevas and P. Würfel, "Charge Carrier Separation in Solar Cells," IEEE Journal of Photovoltaics, vol. 5, no. 1, 2015. pp. 461-469.

[15] K. Masuko et al., "Achievement of More Than 25\% Conversion Efficiency With Crystalline Silicon Heterojunction Solar Cell," IEEE Journal of Photovoltaics, vol. 4, no. 6, 2014, pp. 1433-1435.

[16] E. Shinn, A. Hubler, D. Lyon, M. Grosse-Perdekamp, A. Bezryadin, A. Belkin, "Nuclear Energy Conversion with Stacks of Graphene Nano-capacitors". Complexity. 22 October 2012, 18 (3): pp. 24-27.

[17] Tyagi, Pawan "Multilayer graphene as a transparent conducting electrode in silicon heterojunction solar cells," AIP Advances, AIP ADVANCES 5, 2015, 077165.

[18] Huang X., Xiaoying Q., Boey F. and Zhang H., "Graphene based composites," Chem Soc. Rev., 2012, 41, pp. 666-686.

[19] Miao X., Tongay S., Petterson M., Berke K., Rinzler A., Appleton B., Hebard A., "High Efficiency Graphene Solar Cells by Chemical Doping," Nano Lett., 2012, 12(6), pp. 2745-2750.

[20] Li X., Zhang S., Wang P., Zhong H., Wu Z., Chen H., Liu C., Lin S., "High performance solar cells based on graphene-GaAs heterostructures," Nano Energy, 2015, 16, 310.

[21] Ye Y., Dai L., "Graphene-based schottky junction solar cells," J. Mater. Chem., 2012, 22, 24224.

[22] Zongyou Yin, Jixin Zhu, Qiyuan He, Xiehong Cao, Chaoliang Tan, Hongyu Chen, Qingyu Yan, and Hua Zhang, "Graphene-Based Materials for Solar Cell Applications", Advance Energy Material, 4, 1300574, 2014, pp. 1-19.
[23] B. von Roedern, G.H. Bauer, "Material Requirements for Buffer Layers Used to Obtain Solar Cells with High Open Circuit Voltages", Material Research Society's Spring Meeting, 1999, pp. 6.

[24] B. Samanta, Debabrata Das, A.K. Barua, "Role of buffer layer at the $\mathrm{p} / \mathrm{i}$ interface on the stabilized efficiency of a-Si solar cells", Solar Energy Materials and Solar Cells 46, 1997, pp. 233-237.

[25] J. Melskens, B. W. H. van de Loo, B. Macco, L. E. Black, S. Smit and W. M. M. Kessels, "Passivating Contacts for Crystalline Silicon Solar Cells: From Concepts and Materials to Prospects," IEEE Journal of Photovoltaics, vol. 8, no. 2, 2018, pp. 373-388,

[26] A. Blakers, "Development of the PERC Solar Cell," IEEE Journal of Photovoltaics, vol. 9, no. 3, 2019, pp. 629-635.

[27] Antonino Parisi, Riccardo Pernice, Vincenzo Rocca, Luciano Curcio, Salvatore Stivala, Alfonso C Cino, Giovanni Cipriani, Vincenzo Di Dio, Giuseppe Ricco Galluzzo, Rosario Miceli, Alessandro Busacca, "Graded Carrier Concentration Absorber Profile for High Efficiency CIGS Solar Cells,” 2015 International Journal of Photoenergy, 2015, pp. 1-9.

[28] Peter Colter, Brandon Hagar and Salah Bedair, "Tunnel Junctions for III-V Multijunction Solar Cells Review”, Crystal 2018, 8, 445, 2018, pp. 1-15.

[29] William Shockley and Hans J. Queisser, "Detailed Balance Limit of Efficiency of pn Junction Solar Cells", Journal of Applied Physics, 32 (3), 1961, pp. 510-519.

[30] Harder, N.-P. \& W rfel, P., "Theoretical limits of thermophotovoltaic solar energy conversion", Semiconductor Science and Technology, 18(5), 2003. pp. S151-S157.

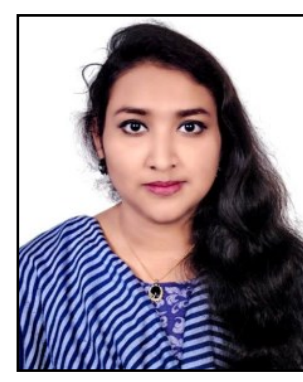

Ashrafun Nushra Oishi received Bachelor of Science (B.Sc.) in EEE from American International University-Bangladesh (AIUB). Her Master Degree is also from AIUB from MEEE Department. She started her career on May 2018 at European University of Bangladesh (EUB) as Lecturer in the Dept. of EEE. Her research interest is focused on Solar Cell, Renewable Energy, Robotics and Control Systems.

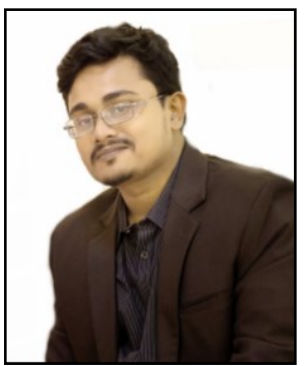

Meer Shadman Shafkat Tanjim received Bachelor of Science in EEE from American International University-Bangladesh (AIUB). His Master Degree is also from AIUB in EEE Background. He started his profession at Bangladesh Institute of Science \& Technology (BIST) as Lecturer in the Dept. of ECE on May 2017. Around November 2017, he switched to European University of Bangladesh (EUB) in the Dept. of EEE as Lecturer. Recently, he is researching on Control System Strategies, Solar \& Wind Energy, Aeronautics, Robotics, Smart System and IoT aspects.

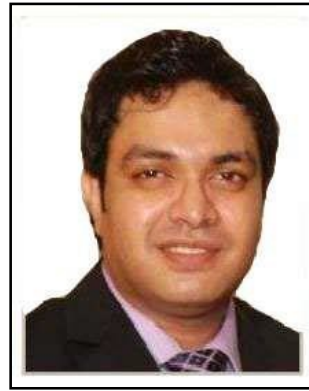

M. Tanseer Ali received Doctor of Engineering degree from University of Greenwich (UK), 2013. His research interest is focused on Analog Electronics, RF/Microwave Circuits and Systems, Nanoelectronics, Nuclear Power, Solid State Circuits. Currently he is working as Senior Assistant professor in the department of EEE, AIUB. 